\title{
El rol de la Secretaría Distrital de la Mujer de la ciudad de Bogotá ante los delitos de violencia sexual
}

The Role of the Women's District Secretariat of Bogotá City in face of crimes of sexual violence

Autor: Fransis Jhojana Garzón

DOI: https://doi.org/10.19053/16923936.v18.n35.2020.11128

Para citar este artículo:

Garzón, F. (2020). El rol de la Secretaría Distrital de la Mujer de la ciudad de Bogotá ante los delitos de violencia sexual. Revista Derecho y Realidad, 18,

(35), 163- 187. 


\section{EL ROL DE LA SECRETARÍA DISTRITAL DE LA MUJER DE LA CIUDAD DE BOGOTÁ ANTE LOS DELITOS DE VIOLENCIA SEXUAL}

The Role of the Women's District Secretariat of Bogotá City in face of crimes

of sexual violence

\section{Fransis Jhojana Garzón}

fransis.garzon@gmail.com

Recepción: 4 de junio 2020

Aceptación: 22 de julio 2020

\section{RESUMEN}

En el siguiente artículo se presentará el panorama general de la atención, por parte de la Secretaría Distrital de la Mujer, a delitos de violencia sexual en Bogotá, enfocado en relación con el marco normativo de la política pública Mujer y Equidad de Género, e identificando las acciones estratégicas de gestión que se pusieron en marcha durante el periodo comprendido entre 2016 y 2019, espacio de gobierno de Enrique Peñalosa. El presente análisis de los hallazgos de dicha funcionalidad estatal, y su investigación, proviene del manejo de documentos de índole normativa, tanto nacional como internacional; fuentes primarias, como entrevistas a funcionarias y ex funcionarias de la Secretaría, evidencia documental a modo de respuesta de derechos de petición de instituciones distritales, que trabajan en conjunto con la Secretaría Distrital de la Mujer, y la atención a víctimas de violencia sexual. A partir de tal investigación se establecieron varios resultados, como: una descripción del funcionamiento de la entidad estatal, análisis de resultados, cuantitativos y cualitativos, de la atención a mujeres víctimas de violencia sexual y las barreras en el acceso a dicha atención.

\section{PALABRAS CLAVES}

Violencia sexual, política gubernamental, derechos humanos de las mujeres, Institución estatal, feminismo.

\section{ABSTRACT}

The following article will present an overview of the Women's District Secretariat attention to crimes of sexual violence in Bogotá, focusing on the regulatory framework of public policy Women and Gender Equality, and identifying the strategic management actions that were implemented during the period between 2016 and 2019, the government space of Enrique Peñalosa. The present analysis of the findings of this state functionality, and 
its investigation, comes from the handling of documents of a normative nature, national and international; primary sources, such as interviews with officials and former officials of the Secretariat, documentary evidence as a response to rights of petition of district institutions, which work in conjunction with the District Secretariat for Women, and the care of victims of sexual violence. Several results were established based on this research, including a description of the functioning of the State entity, an analysis of the results, quantitative and qualitative, of care for women victims of sexual violence and the barriers to access to such care.

\section{KEYWORDS}

Sexual violence, government policy, human rights, State institution, feminism.

\section{INTRODUCCIÓN}

La violencia contra las mujeres constituye una vulneración histórica y sistemática a sus derechos humanos (Canterla, 2002). Por lo cual, a pesar de los importantes avances jurídicos, continúa existiendo una enorme brecha entre el reconocimiento formal de los derechos de las mujeres y la posibilidad de materializar tales a través de su goce efectivo. Asimismo, es posible encontrar acciones u omisiones, como lo es el olvido estatal que se traduce en perjuicios a las familias durante generaciones o el empobrecimiento de las comunidades, que refuerzan la discriminación y otras formas de violencia social. Lo cual obstaculiza las posibilidades conjuntas de desarrollo social y crecimiento económico (Rodríguez, 2017). Dicha violencia, tanto en el ámbito público como el privado, se ha configurado en los países latinoamericanos como una de las problemáticas de mayor magnitud social y política. Ella se manifiesta en las distintas esferas sociales, contextos geográficos, edades, razas, etnias, entre otras formas de categorización social. Su impacto es inmediato y de largo alcance, pues afecta el tejido de las comunidades y el pleno disfrute de la ciudadanía de las mujeres (CominsMingol, 2008).
Una de las causas que posibilita la manifestación de los tipos de violencia contra las mujeres es la cultura patriarcal. Pues, a partir de ella se construye y perpetúa, en su devenir histórico, roles de género que coaccionan a hombres y mujeres a adaptarse a marcadas diferencias en un plano jerárquico de desigualdad social y política (Sequeira y Stella, 2012). De igual modo, en una sociedad como la colombiana, donde perviven profundas desigualdades socioeconómicas, la violencia del hambre y la miseria impacta fuertemente a los infantes y a las mujeres a causa de su condición de vulnerabilidad (Grau, 2013). El patriarcado, o la relación de género basada en desigualdad, es la estructura política más arcaica y permanente de la humanidad. Ello se debe a que moldea la relación categórica en toda configuración de prestigio y poder, pues, aunque capturada, radicalmente agravada y transmutada en un orden de alta letalidad, por el proceso de conquista y colonización, precede como simple jerarquía, convertido en un patriarcado de baja intensidad e impacto, a la era colonialmoderna. La expresión "patriarcal-colonialmodernidad" describe adecuadamente la prioridad del patriarcado de apropiarse del cuerpo femenino y de este como primera colonia (Segato, 2017).

La cultura patriarcal adapta los roles de género dentro de espacios privados (familia) y los relaciona con un tipo de sociedad particular. Con el tiempo, las conductas tipificadas para cada rol se normalizan como un deber social, se castiga su trasgresión y se genera aprobación cuando son apropiadas (Andrieu Sanz, 2005). Por ejemplo, tradicionalmente, las tareas de maternidad y crianza, dentro del ámbito de la biología, son innatas del género femenino, aunque no se les atribuya un valor de progreso social, dado que no goza de reconocimiento monetario o de logro académico (Barrantes, 2016). Elizabeth Jelin (2001) argumenta que: "existe una tendencia generalizada a tener un modelo predominante en el que encajan a las mujeres de acuerdo con unos únicos valores sociales, culturales, éticos y morales de la naturaleza femenina" (p.30). Ello corresponde al modelo clásico del 
rol femenino en la sociedad occidental, en consonancia con el modelo patriarcal, según el cual las mujeres por orden natural poseen marcadas diferencias con el género masculino, lo que les significa asumir roles con menor valía social, política y económica. En consecuencia, la condición femenina se construye con base en la subordinación, el sometimiento y la opresión, es decir, bajo circunstancias de desigualdad. Por lo tanto, el modelo patriarcal designó valores morales que se han normalizado como propios de las mujeres (Jelin, 2001).

Hay una serie de derechos que son afectados por las manifestaciones de los tipos de violencias, para comprenderlas, es necesario realizar un recorrido conceptual e histórico sobre la caracterización de los tipos de violencia contra la mujer y establecerlos en el contexto nacional. Para así, ampliar el análisis crítico sobre las acciones de las instituciones estatales encargadas de prevenir, atender y sancionar los actos delictivos que atentan contra los derechos de las mujeres. Las formas de violencia son caracterizadas en la normatividad de la siguiente manera:

Por violencia contra la mujer se entiende cualquier acción u omisión, que le cause muerte, daño o sufrimiento físico, sexual, psicológico, económico o patrimonial por su condición de mujer, así como las amenazas de tales actos, la coacción o la privación arbitraria de la libertad, bien sea que se presente en el ámbito público o en lo privado, se manifiestan como violencia física, psicológica, sexual y económica. Las mujeres pueden ser víctimas de varias formas de violencia a la vez (Ley 1257 de 2008, Artículo 2 y 3).

En Colombia puede hablarse de una violencia multidimensional y multicausal hacia las mujeres. Dentro de las principales causas se observan las problemáticas económicas; violencia sociopolítica, como producto del conflicto armado; inseguridad, tanto rural como urbana; acceso efectivo a la justicia, enfocado especialmente a la no repetición de los actos delictivos contra las mujeres; violaciones sistemáticas a los
DD.HH, por parte del Estado o de grupos armados al margen de la ley; condiciones deficientes en la educación rural y urbana; falta de garantías con respecto al acceso a los servicios de salud sexual y reproductiva, y la falta de enseñanza con respecto a los derechos de los mismos; altas tasas de desempleo, entre otros aspectos. Los factores anteriormente mencionados demandan la necesidad de una funcionalidad estatal capaz de garantizar condiciones favorables, por medio de las cuales se prevenga toda clase de violencia. En esa medida, la importancia de que los estados cumplan $\mathrm{y}$ hagan respetar los tratados de índole internacional, involucrando de manera progresiva sus contenidos en las estructuras constitucionales, a su vez en las leyes y normativas que se suscriben a esa constitución, se hace indispensable (Garzón, 2020).

En términos generales, dicha violencia constituye un obstáculo que restringe las posibilidades de las mujeres para tomar decisiones en distintos ámbitos. Ello afecta el goce efectivo de sus derechos humanos, por lo cual, la violencia de género, en todas sus manifestaciones, se convierte en un atentado contra la vida, seguridad, cuerpo, desarrollo de la libre personalidad y la salud física y mental, a la vez que dificulta el ejercicio de los derechos sexuales y reproductivos. Todo lo anteriormente mencionado, posiciona un abordaje particular de tal violencia en el país, respecto a su prevención, atención y sanción, que brinde respuestas integrales a las mujeres (Garzón, 2020). La violencia sexual contra las mujeres vista como un problema social y político, requiere una intervención de carácter público, que se inscriba en la agenda del Estado, formulada y estipulada en instrumentos internacionales sobre los derechos humanos de las mujeres (CEDAW, la convención Belém Do Pará, la Plataforma de acción de Beijing 95, Declaración Universal de los Derechos Humanos, entre otras) .Lo cual le da carácter oficial y un compromiso estatal con la normatividad fundante e históricamente garante de los derechos humanos de las mujeres a nivel global. De igual forma, se deben crear e implementar entidades especializadas para la prevención 
y atención de delitos de violencia sexual contra mujeres, niñas y adolescentes, así como fortalecer los organismos que ya están presentes. De allí surge la importancia de analizar, cómo una entidad relativamente reciente, a la Secretaría de la Mujer de la ciudad de Bogotá, la cual ha venido encarando la violencia sexual contra las mujeres.

En la contemporaneidad, los Estados tienen el deber de crear una normativa, y compromisos básicos, capaz de garantizar los derechos femeninos, para lo cual pueden hacer uso de políticas públicas y programas que den cumplimiento a los convenios y tratados internacionales (Chávez Carapia, 2016). Los estándares internacionales, cabe decir, reconocen la violencia contra las mujeres como una forma de discriminación y exigen a los Estados que actúen con la debida diligencia para prevenir, investigar y castigar todos los actos de violencia contra las mujeres, perpetrada por cualquier individuo, incluido el Estado o agentes no estatales (Oficina del Alto comisionado de las Naciones Unidas para los Derechos Humanos, 2019). A razón de ello, es posible afirmar como el Estado colombiano debe comprometerse, desde sus distintas esferas institucionales, a prevenir la violencia contra las mujeres. Sin embargo, más allá de la prevención explicita que se puede evidenciar, por ejemplo, en espacios de sensibilización o acciones pedagógicas, se encuentran los procesos de atención a las víctimas, siendo este el primer paso al acceso a la justicia que sancione los responsables a las violaciones de los derechos humanos de las mujeres.

En la ciudad de Bogotá, la institución encargada de atender, orientar y representar a las mujeres víctimas de violencia sexual, es la Secretaría Distrital de la Mujer, creada en el año 2012 como parte del sector Mujeres del Acuerdo 490 de 2012. En el artículo cinco de dicho Acuerdo se lee sobre la función y naturaleza de dicha Secretaría lo siguiente:

[...] ARTÍ́CUlO 5o. Naturaleza, Objeto y Funciones Básicas de la Secretaría Distrital de la Mujer. La Secretaría Distrital de la Mujer es un organismo del Sector Central con autonomía administrativa $y$ financiera. Tiene por objeto liderar, dirigir, coordinar, articular y ejecutar las etapas de diseño, formulación, implementación, seguimiento y evaluación de políticas públicas para las mujeres, a través de la coordinación intra e intersectorial, territorial y poblacional de estas políticas públicas, así como de los planes, programas y proyectos que le corresponda para el reconocimiento, garantía y restitución de los derechos $\mathrm{y}$ el fomento de las capacidades $\mathrm{y}$ oportunidades de las mujeres. [...]

Por tanto, se tendrá en cuenta el análisis de la política pública Mujeres y Equidad de Género, la composición legal vigente a nivel nacional y el plan de desarrollo distrital 2016-2019, que contiene la estructuración de la política pública actual, fijando la respuesta institucional de la Secretaría Distrital de la Mujer como entidad encargada de:

Liderar, orientar y coordinar la formulación, implementación, seguimiento y evaluación de la Política Pública de Mujeres y Equidad de Género, así como la transversalización de los enfoques de derechos de las mujeres, de género y diferencial, en los planes, programas, proyectos $\mathrm{y}$ políticas públicas distritales, para la protección, garantía y materialización de los derechos humanos de las mujeres en las diferencias y diversidades que las constituyen, promoviendo su autonomía y el ejercicio pleno de su ciudadanía en el Distrito Capital. (Misión Secretaria Distrital de la Mujer, 2019)

El objetivo de la Política Pública de Mujeres y Equidad de Género, que también aparece en la misión de la Secretaría Distrital de la Mujer, consiste en reconocer, garantizar y restablecer los derechos de las mujeres que habitan en la ciudad de Bogotá. De forma tal que se modifiquen, de manera progresiva $\mathrm{y}$ sostenible, las condiciones injustas $\mathrm{y}$ evitables de discriminación, exclusión y subordinación que enfrentan las mujeres en los ámbitos público y privado, promoviendo 
verdadera igualdad de oportunidades y equidad de género en el Distrito Capital.

\section{METODOLOGÍA}

Los aportes metodológicos de la investigación previa a la materialización del presente artículo fueron de índole cualitativa, provenientes de fuentes primarias, más exactamente de entrevistas a funcionarias y ex funcionarias de la Secretaría Distrital de la Mujer. Asimismo, se tomó en cuenta evidencia documental oficial, como respuesta a derechos de petición en torno a cómo se trata la violencia sexual por las entidades distritales de Bogotá: la Secretaría Distrital de la Salud, la Secretaría de Educación, la Secretaría Distrital de Seguridad, Convivencia y Justicia, y la misma Secretaría Distrital de la Mujer. En lo que respecta a los métodos, se optó por la entrevista, puesto que, al ser una técnica personal, permite la recolección de la información a profundidad a la vez que indaga en aspectos cualitativos (Domingo Carbonero Muñoz y Neus Caparrós, 2015). En dicha técnica, el informante expresa o comparte oralmente, y por medio de una relación interpersonal con el investigador, su saber sobre el tema, donde muestra opiniones, creencias, puntos de vista y actitudes.

Por lo cual, en la presente metodología resulta primordial la forma en la cual se realizan las preguntas. La entrevista es fundamentalmente cualitativa, dado que el informante posee mayores posibilidades de expresión, lo cual llena a una comprensión más profunda de sus puntos de vista, actitudes, sentimientos e ideas. A razón de ello, se convierte en un medio de hacer investigación de manera personal y profunda, contrario al método de encuesta, pues, a razón de sus preguntas abiertas, las respuestas obtenidas abren oportunidades de indagación. Las preguntas de las entrevistas estuvieron enfocadas en las siguientes categorías de análisis: 1) Prevención de la violencia sexual. 2) Trabajo transversal entre la Secretaría Distrital de la Mujer y otras entidades. 3) Atención a víctimas de violencia sexual. 4) Instrumentos y estrategias utilizadas por las distintas entidades en pro de prevenir la violencia sexual. 5) Ejecución de la política pública Mujeres y Equidad de Género. Categorías que serán analizadas a la par, dando énfasis a la atención a los delitos de violencia sexual en el capítulo tercero y cuarto, junto a las respuestas de los derechos de petición ya mencionados.

\section{VIOLENCIA CONTRA LA MUJER Y VIOLENCIA SEXUAL EN BOGOTÁ: DESARROLLO Y TEORÍAS APLICADAS AL ANÁLISIS}

La Ley 1257 habla de violencias contra las mujeres, en plural, impulsando la consigna política y social de que no hay una sola forma de violencia contra las mujeres, dándole carácter de violación de derechos humanos, esta Ley le da estatus y legítima en el ordenamiento jurídico estos delitos, a su vez se convierte en un tema de interés público, saliendo del marco del espacio privado y las dinámicas intrafamiliares. La Ley 1257 funcionan como instrumento recolector de las denuncias por parte del movimiento de mujeres, aquellas relacionadas con las afectaciones violentas. Ella materializó en su contenido las expresiones femeninas de hacer política, teniendo en cuenta un consenso general, superando diferencias, en donde se compromete a cumplir una agenda con las peticiones consagradas. La convención de Belem do Pará, aprobada en Colombia mediante la Ley 248 de 1995, define en su primer capítulo el ámbito de aplicación y la forma en la que la violencia contra la mujer debe entenderse como cualquier acción o conducta, basada en el género, que cause muerte, daño o sufrimiento físico, sexual o psicológico contra el género femenino, tanto en el ámbito público como en el privado. La Ley 1257 trata las violencias contra las mujeres, en plural, puesto que impulsa la consigna, política y social, de la multiplicidad de formas de violencia contra las mujeres. Ello le da carácter de violación a los derechos humanos, dándole así, estatus y legitimación a estos delitos dentro del ordenamiento jurídico. Por lo cual, se convierte en un tema de interés público, saliendo del marco privado y las dinámicas intrafamiliares. 
Otro aporte de la Ley en cuestión se refiere a su segundo artículo, puesto que, en él se da la categorización conceptual de las distintas formas de violencia y discriminación de la cual sufren las mujeres. Ello permite establecer las siguientes definiciones de daño: a) daño psicológico b) daño o sufrimiento físico: riesgo o disminución de la integridad corporal de una persona, c) daño o sufrimiento sexual y d) daño patrimonial. (Congreso de la República, 2008). Por otro lado, es posible contemplar unas de las expresiones más intensas de la violencia: el feminicidio. A pesar de la consideración de que no existe una forma de medir las violencias, o jerarquizarlas, ya que cada una, indistintamente, afecta de diversas formas a las mujeres, el feminicidio en Colombia se encuentra tipificado bajo la Ley 1761, o Ley Rosa Elvira Cely, el cual es reconocido como delito autónomo. El feminicidio es el asesinato de mujeres por el simple hecho de serlo. Es la manifestación de la violencia patriarcal que se realiza bajo el fin de "ajusticiar" a las mujeres que no encajan en el rol preestablecido socialmente para su género. Por ello mismo, podría decirse que son asesinadas como una demostración de la no pertenencia de su cuerpo, y como este le pertenece a otros.

En otros términos, el feminicidio es el asesinato violento a mujeres, teniendo en cuenta que dicho delito puede encontrarse precedido por una cadena o serie de diversas violencias, precedidas por un fuerte asidero en patrones culturales. Significar las experiencias de las mujeres, desde las construcciones teóricas feministas, permite que el término "feminicidio" ponga en claro el papel de víctima y victimario. Se diferencia del concepto de "homicidio", entendido por la muerte infligida a una persona en forma intencional e ilegal, por otra u otras (Interior, 2017). El feminicidio se relaciona con conductas exteriorizadas por convicción. El victimario se encuentra convencido de su necesidad por humillar, golpear y asesinar a una mujer. Tal construcción mental depende de su rol de género asignado socialmente, es decir, agrede y mata por ser mujer (Montoya, 2017). El concepto de feminicidio se encuentra apenas en construcción. No obstante, claramente enmarca una serie de fenómenos que inician en la violencia sistemática a la dignidad, libertad e igualdad de la mujer. La cual, silencia a la víctima por medio de los actos de control y sometimiento, que encuadra la discriminación. Cuando la víctima reacciona, comienza su proceso de expresión, donde habla, exige sus derechos y denuncia su maltrato, mediante lo cual, pasa a una segunda etapa donde se reactiva la violencia. Es la fase de reincidencia y termina el ciclo con el fin de la existencia de la mujer (Montoya, 2017).

El asesinato de un sujeto por su condición de ser mujer se introdujo, por primera vez, en el Código Penal colombiano como un agravante de la conducta típica de homicidio, consagrada en el artículo 103. El numeral 11 del artículo 104 del código fue adicionado a través del artículo 26 de la Ley 1257 de 2008. La Ley 1257 estableció "normas de sensibilización, prevención y sanción de formas de violencia y discriminación contra las mujeres" e introdujo el feminicidio para aquellas situaciones en las que "se cometiere [el homicidio] contra una mujer por el hecho de ser mujer" (Rodríguez G. P., 2016). Por otro lado, el daño, o sufrimiento, sexual puede entenderse como la consecuencia proveniente de la acción de obligar a una persona a mantener contacto sexualizado, ya sea de carácter físico o verbal, o de participar en otras interacciones sexuales mediante el uso de fuerza, intimidación, coerción, chantaje, soborno, manipulación, amenaza o cualquier otro mecanismo que anule o limite la voluntad del individuo. Asimismo, se considera daño, o sufrimiento, sexual el hecho de que el agresor obligue a la agredida a realizar alguno de estos actos con terceras personas (Ley 1257 de 2008, Artículo 3). La violencia sexual se ejerce cuando se obliga a hacer una acción corporal, física o sexual a un sujeto sin su consentimiento previo. Entre esto se incluye tocar alguna zona de su cuerpo, insertar algún objeto, mostrar imágenes o videos sin el consentimiento explícito del involucrado, al igual que dicho acuerdo voluntario puede verse afectado si el sujeto en cuestión se encuentra bajo la influencia del alcohol o alguna sustancia alucinógena. 
De esa forma, la violencia sexual es la acción que consiste en obligar a una persona a mantener contacto sexual, físico o verbal, o a realizar otras interacciones sexuales mediante el uso de fuerza, intimidación, coerción, chantaje, soborno, manipulación, amenaza o cualquier otro mecanismo que anule o limite la voluntad personal. Igualmente, se considera violencia sexual cuando la persona agresora obliga a la agredida a realizar alguno de estos actos con terceras personas. En este tipo de violencia se incluyen los tocamientos y manoseos, obligar a las mujeres a tener relaciones sexuales u obligar a las mujeres a llevar a cabo actos sexuales que ellas no quieren (Educación, 2019). Tal definición llega a ser un referente, como algunos otros, de su significado a nivel oficial. Sin embargo, en el presente análisis se dará mayor relevancia a la definición propuesta por la Ley 1257 del 2008 que plantea:

que la violencia sexual es la acción que consiste en obligar a una persona a mantener contacto sexual, físico o verbal, o a participar en otras interacciones sexuales mediante el uso de fuerza, intimidación, coerción, chantaje, soborno, manipulación, amenaza o cualquier otro mecanismo que anule o limite la voluntad personal. Igualmente, se considera violencia sexual cuando la persona agresora obligue a la agredida a realizar alguno de estos actos con terceras personas. En este tipo de violencia se incluyen los tocamientos y manoseos, obligar a las mujeres a tener relaciones sexuales u obligar a las mujeres a llevar cabo actos sexuales que ellas no quieren. (p. 13)

Dado que, aquí se incluye las diferentes manifestaciones de la violencia sexual dadas en aproximación al contexto nacional. La violencia sexual contra la mujer se configura como una relación de dominación y subordinación, y puede ser vinculado al estímulo que genera el poder, la fuerza, el control y la capacidad de humillación. Las motivaciones que impulsan a perpetrar estos actos son diversas, puesto que van desde la resolución agresiva de conflictos internos, y el poco control de la conducta, hasta intereses vinculados a la ratificación del poder masculino sobre la mujer, situación que se refuerza con la creencia, común en muchos agresores, que a la mujer le agrada la coacción sexual (Aguilar, 2010).

Por ello mismo, la violencia sexual se ha convertido en tema de discusión en distintos escenarios, lo cual, genera referentes más detallados sobre sus tipologías, características y las obligaciones del Estado sobre la atención y prevención de dicho fenómeno. Resulta preciso situar los DD. HH femeninos desde la perspectiva estructural, puesto que, brinda una visión feminista y con enfoque de género. Ello se debe a la forma en la que vincula aportes conceptuales y académicos, de distintas vertientes feministas, al derecho, la legislación y las diferentes expresiones jurídicas de las ramas, tanto nacional como internacionalmente. El feminismo visibiliza a las mujeres, así como su aporte en la sociedad, pues al "reconocer y nombrar otorga existencia social, y la existencia es un requisito para la autovaloración y para la reivindicación" (Jelin, 1996, p. 197).

\section{SECRETARÍA DISTRITAL DE LA MUJER: LA EXIGIBILIDAD DE DERECHOS TOMA FORMA INSTITUCIONAL}

Dentro del Plan de Desarrollo Económico, Social, Ambiental y de Obras Públicas para Bogotá D.C. 2016 - 2020 "Bogotá Mejor Para Todos", en lo que estipula el Acuerdo 645 de 2016 en el artículo 20, se contempla como objetivo cerrar brechas de género en trabajo, educación, empleo, emprendimiento, salud, participación y representación en espacios de incidencia política y de construcción de paz, y actividades recreo deportivas. Ello con el fin de avanzar hacia el desarrollo pleno del potencial de la ciudadanía, a través del desarrollo de capacidades de las mujeres para acceder e incidir en la toma de decisiones sobre los bienes, servicios y recursos del distrito capital. La Secretaria Distrital de la Mujer, propenderá por la participación de las mujeres en cargos de nivel directivo 
en el sector central y descentralizado de la administración distrital. El primer objetivo estratégico, mencionado en el apartado de los objetivos estratégicos contenidos en el plan 2017 - 2020 de la Secretaría de la Mujer, propone: "Contribuir con la prevención y atención de las violencias contra las mujeres en sus diferencias y diversidades en el Distrito Capital, en articulación con los demás sectores de la Administración distrital y las autoridades competentes". Lo cual centra el objeto de análisis alrededor de la atención a mujeres víctimas de violencia sexual. Por parte de la Secretaría de la Mujer, las estrategias de atención que se enmarcan en este objetivo son una serie de acciones orientadas a su cumplimiento, tales como la intervención especializada socio-jurídica de la estrategia litigio, que ofrece orientación, asesoría y representación en las Casas de Igualdad de Oportunidades y Casas de Justicia.

Por otro lado, las Casas Refugio brindan acogida, protección, asesoría y asistencia técnico-legal a mujeres en el marco del desarrollo e implementación del sistema SOFIA, (Sistema Orgánico, Funcional, Integral y Articulador). Cuyas obligaciones se dan en materia de prevención, atención, sanción, erradicación y reparación de las violencias contra las mujeres tanto en el ámbito público como en el privado, así como promover el cumplimiento de la Ley 1257 de 2008 en la ciudad de Bogotá (Secretaria Distrital de la Mujer, 2019). Dentro del Plan de Desarrollo Económico, Social, Ambiental y de Obras Públicas para Bogotá D.C. 2016 - 2020 "Bogotá Mejor Para Todos", en lo que estipula el Acuerdo 645 de 2016 en el artículo 30 se proyectó el fortalecimiento a la atención integral del sistema SOFIA. Lo cual asegura la coordinación interinstitucional para la efectiva implementación de estrategias de prevención, atención y protección integral, y el restablecimiento de derechos a mujeres en riesgo o víctimas de violencias. Dicho objetivo intenta crear las condiciones para hacer de Bogotá un territorio seguro y accesible para las mujeres, libre de violencia en los espacios públicos y privados, donde todas las mujeres puedan disfrutar de la ciudad y el territorio sin miedo.
El compromiso particular de atención y erradicación de la violencia sexual que adquiere la secretaria de la Mujer con la Política Pública de Mujeres y Equidad de Género, también se evidencia en el Decreto 166 de 2010 artículo 7 literal E en donde se afirma: "La responsabilidad institucional $y$ estatal de erradicar progresiva y sosteniblemente, las formas de violencia sexual contra las mujeres en los ámbitos político, comunitario, familiar y de pareja en el espacio público y privado para el ejercicio pleno de sus derechos". Para cumplir con este compromiso dentro de las estrategias del objetivo, se institucionalizaron espacios de acompañamiento y atención para mujeres víctimas de violencia sexual. Las Casas de Igualdad de Oportunidades para las Mujeres, son un modelo de atención que promueve el empoderamiento de los derechos de las mujeres y, a su vez, son el mecanismo privilegiado de la territorialización de la Política Pública de Mujeres y Equidad de Género, para garantizar, acompañar y prestar servicios para las mujeres que habitan en Bogotá (Secretaría Distrital de la Mujer, 2019). Las CIO (Casas de Igualdad de Oportunidades), se institucionalizaron en cabeza de la Secretaría Distrital de la Mujer, mediante el Acuerdo 583 de 2015 del Concejo de Bogotá. Desarrollan, hasta el momento, acciones y estrategias socio-jurídicas para que las mujeres víctimas de violencia sexual denuncien, minimizando el silencio y la tolerancia que existe frente a las situaciones y sus contextos. A la vez que orienta a las víctimas para que, mediante herramientas, accedan a la justicia, propendiendo por el reconocimiento, garantía y restablecimiento de sus derechos, como se menciona en el artículo 6.C y artículo 3 de dicho decreto (Bogotá, 2015).

Por otro lado, dentro el marco de articulación del sistema SOFIA, las Casas de Justicia, 6 en Bogotá, ubicadas en las localidades de Usaquén, Mártires, Usme, Kennedy, Suba y Chapinero, también desempeñan la función de atención a mujeres víctimas de violencia sexual. Ya que se conciben como centros interinstitucionales de orientación, referencia y atención para facilitar el acceso 
de la población de determinada localidad a servicios de justicia formal y no formal. Allí las usuarias encuentran atención gratuita a sus inquietudes y requerimientos (Ministerio de Justicia, 2020). Las Casas de Justicia son escenarios interinstitucionales en donde confluyen entidades como la Fiscalía General de la Nación, la Defensoría del Pueblo, la Personería de Bogotá, la SD Mujer, la Comisaría de Familia, entre otras. En ellas se busca garantizar a la ciudadanía el acceso eficiente y oportuno a la justicia. Mediante un convenio interadministrativo con Secretaría de Seguridad, convivencia y justicia, la estrategia brinda asesoría y orientación a las mujeres que han sido víctimas de violencia (Secretaría Distrital de la Mujer, 2019). La Secretaría, en el periodo inicial de funcionamiento, consideró un enfoque diferencial y de derechos en las atenciones. Dicho enfoque se centra en el contexto social, político, geográfico, cultural y los determinantes sociales relacionados con condiciones de discapacidad, etnia, orientación sexual, situación económica, desplazamiento forzado, entre otras. El enfoque diferencial identifica las diversidades, desigualdades e inequidades sociales, culturales y económicas de las mujeres, que impiden el ejercicio pleno de sus derechos. Ello con el propósito de incorporar acciones afirmativas para una adecuada atención en casa refugio, basada en las necesidades e intereses particulares, así como la aplicación de métodos diferenciales para proteger y garantizar sus derechos humanos. Tal enfoque se convierte en una herramienta de análisis y guía para la acción social y política. La cual tendrá en cuenta las diferencias y diversidades de las mujeres y su entorno familiar, así como sus intereses estratégicos, para la eliminación de la discriminación, segregación y marginación, abordando las diferentes formas de exclusión que operan de forma simultánea -clase, raza, etnia, orientación sexual, identidad de género, ciclo vital, etc. (Concejo Distrital de Bogotá, 2015).

Dicho enfoque se encuentra presente en la atención a mujeres víctimas de violencia sexual y, a su vez, víctimas de otros hechos victimizantes como el desplazamiento forzado, en el marco del conflicto armado interno colombiano. El fenómeno en cuestión se debe a que las Casas Refugio son un escenario principal para el cumplimiento de las medidas de protección y atención integral. Son lugares dignos y seguros para vivir temporalmente que cubren las necesidades básicas de alojamiento alimentación y transporte de las mujeres víctimas de las diferentes formas y tipos de violencia, junto con sus hijas e hijos, si los tienen. De igual forma, brindan ayuda en la construcción y reconstrucción de sus proyectos de vida a través de asesoría y asistencia técnico legal, gratuita y especializada, acompañamiento psicosocial, psicopedagógico y ocupacional. Lo cual garantiza la seguridad, la interrupción del ciclo de violencia y la promoción de la restitución de sus derechos a partir del reconocimiento y potenciación de sus capacidades, habilidades, y el fortalecimiento de su autoestima y toma de decisiones, bajo el principio, entre otros, de la corresponsabilidad (Concejo Distrital de Bogotá, 2015).

\section{INSTRUMENTOS LEGALES Y ESTRATEGIAS DE ATENCIÓN UTILIZADAS POR LAS DISTINTAS ENTIDADES EN MATERIA DE DELITOS DE VIOLENCIA SEXUAL: TRANSVERSALIZACIÓN Y ARTICULACIÓN}

La implementación de la política pública Mujer y Equidad de Género, genera un vínculo entre el Estado y la sociedad, el primero como lugar de la génesis de la política y el segundo como el retrato de los diferentes contextos y actores sociales hacia dónde se direcciona dicha política. En esa medida, una política pública no se encuentra aislada e independiente de ese contexto, sino que se concreta y materializa en diversas acciones, programas y estrategias dadas en diferentes instituciones, las cuales se convierten en actores estratégicos de articulación para la implementación de la política. Entre los años de 2016 a 2019, la Secretaría Distrital de Salud expresó en respuesta de su derecho de petición, en cuanto a estrategias 
e instrumentos no solo para encarar la violencia sexual sino en general para brindar capacitación y formación en derechos, como viene desarrollando acciones de sensibilización, capacitación y formación desde los enfoques de derechos de las mujeres, género y diferencial, a servidores y colaboradores de las Subredes Integradas de Servicios de Salud. Entre ellas se destacan: 1) Asistencia técnica a los equipos del espacio vivienda. 2) Asistencia técnica a los equipos del espacio público; acción integrada 1 y 2 , en cuanto a la promoción de la salud. 3) Inclusión y desarrollo en el Plan institucional de capacitación PIC liderado por la Dirección de Gestión del Talento Humano de capacitación en género y no violencias contra las mujeres. 4) Asistencia técnica a los equipos de los Centros de Orientación información en Salud (COIS), Centros Locales de Atención a Víctimas (CLAVS), desde la Dirección de Participación y la Subsecretaría de Salud Pública sensibilizando. 5) Talleres de enfoque diferencial, poblacional y de género, modelo integral de atención en salud y rutas de atención dirigidos a las IPS Públicas.

De acuerdo con lo manifestado por la Secretaria Distrital de Salud, en respuesta de la petición (2019), ha venido dando cumplimiento a la Política Pública de Mujer y Equidad de Género, mediante acciones que garantizan los derechos de las mujeres a través de acciones y actividades concertadas por el Sector Salud en el marco de la operación del Plan de igualdad de Oportunidades para la Equidad de Género (PIOEG), y del Plan Sectorial de Transversalización de la Igualdad de Género (PSTIG). La Secretaría Distrital de Salud prioriza el trabajo correspondiente a las mujeres en seis derechos fundamentales: salud plena, paz y convivencia social, vida libre de violencias, cultura libre de sexismo, trabajo, y participación política. En lo que respecta a la atención a mujeres víctimas de violencia sexual, la Secretaria de Salud menciona que su respuesta institucional es desarrollada con los siguientes elementos: una Política en Atención Integral de Salud (PAIS) y un Modelo Integral de Atención en Salud y Rutas Integrales Atención en
Salud - (RIAS). De igual forma manejan en sus procesos de vigilancia un Sistema de Vigilancia Epidemiológica entre los que se encuentran los casos de violencia sexual, lo cual les permite activar rutas intersectoriales de canalización y atención de situaciones relacionadas con los delitos de violencia sexual. Mediante ello se ejecuta de manera funcional parte de la articulación estratégica con la SDM en la atención en materia de estos delitos.

Por otro lado, existe una línea de apoyo y ayuda Psicosocial, la línea 106, que atiende las afectaciones psicosociales relacionadas con Violencia Sexual. Es necesario aclarar que las medidas de atención con mujeres víctimas de violencia sexual, son operadas por Empresas Promotoras de Salud (EPS), ya que las IPS prestan en primera instancia los servicios inmediatos y de urgencia, que requieren las víctimas, las cuales son emitidas por jueces o comisarios de familia. Es decir, que la atención en salud depende de la decisión de alguna de estas instancias. Ha de suponerse que, en este contexto, la presencia de la estrategia de justicia de la SDM debe ser notable. La Secretaria de Salud, adopta el Protocolo y Modelo de Atención Integral en Salud para mujeres en condición de discapacidad, víctimas de Violencia Sexual (Resolución 459 de 2012), en donde son las IPS las encargadas de la atención individual. Aunque persiste la insuficiencia de información sobre las personas con discapacidad, es conocido que este grupo poblacional se encuentra sometido a una vulnerabilidad social específica que lo expone de forma particular a la violencia sexual. La carencia de datos cuantitativos, el subregistro, la impunidad y la falta de denuncia de las diferentes formas de agresión, y en especial la violencia sexual ejercida contra las personas con discapacidad, no solo han contribuido al ocultamiento de un problemática con consecuencias profundas y estructurales en la vida de las personas, sus familias y cuidadores, sino que a su vez son el resultado de una serie de imaginarios respecto a su sexualidad, sus voluntades, sus formas de consentimiento y en últimas su acceso a la ciudadanía (Profamilia, 2019). 
La Secretaría Distrital de Seguridad y Justicia, por su parte, comunica que dicha entidad celebró el Convenio Interadministrativo 727 de 2018 con la Secretaría Distrital de la Mujer y la Secretaría Social, con el objetivo expreso de fortalecer la atención a mujeres víctimas de violencia en el ámbito comunitario -es decir, fuera del ámbito familiar-y de asegurar tanto apoyo psicológico como con el direccionamiento y orientación jurídica. Menciona también, que hubo una acción articulada con la Secretaría de la Mujer para diseñar unos módulos que formarán a los operadores que reciben llamadas al 123, con el propósito de fortalecer la atención a mujeres víctimas de violencias. Por último, tenemos la comunicación y respuesta de la Secretaría Distrital de Gobierno, la cual menciona en los derechos de petición que ha desarrollado una gestión que articula, de manera intersectorial, el desarrollo del plan de acción del Consejo Distrital de Atención a Víctimas de Violencia Intrafamiliar y Explotación Sexual. Por otro lado, lidera La Estrategia de Atención a Víctimas de Violencias en Razón a su orientación Sexual e Identidad de Género, Casa Refugio LGBTI, que se encuentra dirigida a personas con orientaciones sexuales diversas e identidades de género no hegemónicas que se encuentren en situación de vulnerabilidad o han sido víctimas de violencia por esta causa.

En cuanto al trabajo de articulación con otras entidades, la Secretaría Distrital de la Mujer enfatiza en la respuesta de su derecho de petición, que, en el marco del Sistema Distrital Orgánico, Funcional, Integral y Articulador en materia de prevención, atención, sanción, erradicación y reparación de las violencias contra las mujeres SOFIA, realiza acciones colaborativas con otras entidades del Distrito. En particular, destaca el sistema de alertas tempranas en instituciones educativas públicas y privadas asociadas a violencias de género, incluida la violencia sexual en el marco del Subsistemas de Información SIVIM. De igual modo, enfatiza que se realiza articulación y coordinación con las Comisarías de Familia a cargo de la Subdirección para las familias de la Secretaría Distrital de Integración Social, con el Instituto Distrital de Protección de la Niñez y la Juventud IDIPRON en el marco de la Mesa de Explotación Sexual Comercial de Niños, Niñas y Adolescentes ESCNNA, con Medicina Legal, Fiscalía y el Sector Gobierno, encaminada a la articulación y coordinación de acciones asociadas a las rutas de prevención y atención. Es importante señalar que la Secretaría Distrital de la Mujer no atiende a menores de edad, por cuestión de competencias, por lo que dicha atención la realiza el ICBF (Instituto Colombiano de Bienestar Familiar). No obstante, desde el área psicosocial se tiene la oportunidad de hacer una atención psicosocial, por primera y única vez, a mujeres, o a adolescentes en este caso, mayores de catorce años. Luego de lo cual, se redireccionan a los CAIVAS o con el mismo ICBF. Dicha segmentación poblacional por competencias no es negativa ni inadecuada, siempre y cuando se presente bajo el redireccionamiento indicado, de forma que las niñas y adolescentes pueden ser atendidas por especialistas apropiados, por parte de instituciones que también trabajan desde la Política pública de Mujer y Equidad de Género.

\section{REFLEXIONES SOBRE LA ATENCIÓN A MUJERES VÍCTIMAS DE VIOLENCIA SEXUAL POR PARTE DE LA SECRETARÍA DISTRITAL DE LA MUJER}

La violencia contra las mujeres, niñas y adolescentes, particularmente la de carácter sexual, se considera un problema público en materia de derechos humanos. Ha tenido reconocimiento a nivel internacional $y$ los Estados están obligados a reconocer bajo la vigencia de unas normativas que permitan asumirlos como una trasgresión a los DD.HH. Ello se debe a que la violencia sexual afecta de manera crítica a quien la sufre, su incidencia supera el ámbito privado, involucra a múltiples actores, afecta a familias y comunidad. Por lo tanto, su erradicación exige la acción conjunta de diferentes instituciones sociales, tanto del sector estatal como privado. Como se describió previamente, hubo una articulación entre instituciones a nivel distrital, que 
permitió ejecutar acciones diversas en el cumplimiento de los objetivos estratégicos de la Secretaría Distrital de la Mujer. En relación con la prevención y atención a los delitos de violencia sexual, dicha articulación entre entidades y la gestión directa de la Secretaría, deben revelar una estadística anual sobre el número de mujeres atendidas, contrastado con el número de mujeres que llegaron a iniciar un proceso de denuncia. Por lo tanto, se pretende a continuación revelar estas cifras dadas en documentos e informes de tipo oficial, para detectar cuáles son los resultados de la respuesta institucional y analizar los aciertos y deficiencias en el cumplimiento.

Los datos estadísticos relacionados con denuncias se toman del Forensis, publicación anual emitida por el Instituto Nacional de Medicina Legal, donde se exponen datos relacionados con las denuncias ante las autoridades competentes, puntualmente los dictámenes realizados en el Instituto en Bogotá. Lo que no coincide con la cifra total de los delitos en materia de violencia sexual que se debió registrar de las denuncias, ya que, según la tipología de la Violencia Sexual anteriormente descrita, no todas las manifestaciones de violencia sexual requieren valoraciones medicolegales. Sin embargo, dicha entidad, reportó una tasa de 43,90\% exámenes medicolegales por presunto delito sexual por cada 100.000 habitantes, correspondiente a 21.339 casos, con un decremento de 2,06 puntos representados en 546 casos por debajo de los registrados en el año 2015 (Instituto Nacional de Medicina Legal, 2016). De las 26.065 valoraciones por presunto delito sexual registradas durante el año 2018, el $85,6 \%$ de las víctimas fueron mujeres, 22.309 casos, con una tasa por 100.000 habitantes de 88,43, y el 14,4\% fueron hombres, 3.756 casos, con una tasa por 100.000 habitantes de 15,26 . Por cada hombre víctima de presunto delito sexual se presentan seis mujeres víctimas (Instituto Nacional de Medicina Legal y Ciencias Forenses, 2018).
Para 2018, en Bogotá, se reportaron en la estadística del Forensis por realización de exámenes medicolegales por presunto delito sexual a mujeres, una cifra de 3.514 . En contraste con la cifra que arroja el informe de gestión de la Secretaría Distrital de la Mujer, el cual menciona que la meta 2 de la estrategia de Justica de Género, fue representar 726 casos jurídicamente de violencias contra las mujeres en el Distrito Capital de los cuales se atendieron 36 en materia de delitos de violencia sexual. Para el año 2019, no se tiene aún emitido de manera oficial un informe Forensis, por parte del Instituto de Medicina Legal y Ciencias Forenses. Se seleccionó como cifra de recepción de denuncia los casos efectivos de violencia sexual en mujeres, arrojados por la Investigación Epidemiológica de Campo, que proporcionó la Secretaría de Salud a través de la respuesta a derecho de petición. Se relaciona que para el año 2019 hubo una cifra de 2332 de casos efectivos. El periodo de estudio comprende un total de 12.957 casos de violencia sexual reportados oficialmente como un universo de casos en la ciudad de Bogotá. De esos casos en el en el informe de gestión 2016-2019 las Secretaría Distrital de la Mujer de Bogotá se encuentra que en atención psicosocial el $10 \%$ de estas intervenciones se hizo a los casos de violencia sexual, el $5 \%$ en la estrategia de litigio y específicamente en las casas de refugio no se hace un reporte de violencia sexual sino de cobertura de atención por violencia intrafamiliar que es del 83\%. Lo cual indica que de las 27.928 mujeres atendidas en la dupla de atención psicosocial (Secretaría Distrital de la Mujer, 2019), este número de mujeres reportadas en términos de atención por violencia sexual corresponde a 2.792 mujeres atendidas por dupla psicosocial, de las cuales sólo 25 llegan a la estrategia de litigio frente a la exigibilidad judicial de sus derechos y la representación judicial.

Ello refleja la alta cobertura en términos de atención psicosocial, no obstante, resulta muy baja a la hora de hacerse representación judicial. Varios factores inciden en este resultado. El primero de ellos es la apropiación de la violencia sexual como un acto simbólico aceptado por la mujer 
en su condición de esposa, hija, hermana, novia, compañera, ciudadana. Lo cual se remite a los conceptos que, como el de Rita Segato (2010), se aplican a la mujer frente al ejercicio del poder y su aceptación misma en las realidades sociales y culturales. La Secretaría Distrital de la Mujer y las otras entidades abordadas, no mencionaron en cada uno de los puntos indagados de los derechos de petición, los limitantes han tenido durante el presente gobierno distrital, por lo que, siendo una respuesta oficial e institucional, mediante la cual la institución pueda mostrar los aspectos positivos de su trabajo, quedan invisibilizadas las limitantes de los programas y las estrategias. Sin embargo, en las entrevistas realizadas se obtiene algo de luz al respecto, y si bien tres entrevistas no pueden dar una visión generalizada, sirven para arrojar algo de luz y encontrar argumentos determinantes que den cuenta de la baja cobertura de atención. El impacto de atención de la estrategia de Justicia para las mujeres víctimas de delitos de violencia sexual en el contexto territorial y periodo de tiempo señalado, tuvo bajas cifras de atención anual registradas en los documentos oficiales.

Por lo que, para analizar la respuesta institucional dada, es necesario tener en cuenta y reflexionar acerca de cuáles son los obstáculos que no permiten generar una atención integral y completa en el paso por las rutas y protocolos dispuestos. Para muchas mujeres, tomar la decisión de denunciar puede tardar años, debido a la multiplicidad de dificultades que deben afrontar, en primera instancia y el grave impacto que la violencia sexual genera en sus vidas. El temor presentado ante algunos momentos de la atención o los procesos surge a partir de la estigmatización por parte de los profesionales que atienden. Por lo tanto, aunque es notable las buenas prácticas enfocadas en los derechos de género que presenta la Secretaría de la Mujer, es necesario tener en cuenta que, en el Sistema Orgánico, Funcional, Integral y Articulador (SOFIA), hay un horizonte de transversalización en las atenciones que implica un trabajo cooperativo de instituciones de articulación y gestión, en el cual puede presentarse dificultades o situaciones de revictimización. La victimización tiene tres dimensiones: victimización primaria, la cual es generada por el victimario al ocasionarle el daño, ya sea físico, psicológico, patrimonial o sexual. La victimización secundaria, la que le ocasiona el sistema jurídico-socialasistencial. En donde, se evidencia en las múltiples ocasiones en las cuales la víctima debe relatar lo que le sucedió y someterse a exámenes físicos o psicológicos. La victimización terciaria, aquella que provoca la sociedad al recriminarle y culpabilizarla por el hecho que sufrió (Comisión Nacional De Género De La Rama Judicial, 2016).

El número de mujeres que acceden a los servicios de la Secretaría Distrital de la Mujer es alto en cobertura de atención en violencia sexual por atención psicosocial, el cual representaría el 21,55\% del universo de casos. Sin embargo, sólo el $0,7 \%$ de las mujeres acceden a la representación judicial. Lo cual, igualmente afecta derechos fundamentales como el de la verdad y la justicia para las mujeres víctimas, eleva ciclos de impunidad y genera condiciones de frustración y decepción que perpetúan la presencia de la violencia sexual en nuestra sociedad. La partida presupuestal o la ausencia de rubros destinados a desarrollar acciones institucionales, es una dificultad visible en la atención de las profesionales que se encuentran en las CIO (Casa de Igualdad de Oportunidades). Dicha dificultad, no permite visibilizar un gran impacto en las cifras de mujeres atendidas, a la vez que genera reflexión sobre lo que implica una baja capacidad de ejecución. Sumado a ello, existen empleados que se encuentran vinculados a través de un contrato por prestación de servicios, lo cual genera la asignación de contratos cuando haya cambios ligados a la administración y a la política y falta de continuidad en los procesos.

\section{EXPERIENCIAS DE POLÍTICA PÚBLICA EN PREVENCIÓN Y ATENCIÓN DE LA VIOLENCIA}




\section{SEXUAL CONTRA LAS MUJERES EN OTROS PAÍSES: BRASIL Y MÉXICO}

\section{Brasil}

Por un lado, la Ley 11340 Maria da Penha del 2006, reconoce el derecho de todas las mujeres a vivir una vida sin violencia y considera este tipo de agresión como un atentado a los derechos de las mujeres en ese sentido. La Ley obliga al Estado, y a la sociedad, a proteger a las mujeres de la violencia en el espacio privado, independientemente de su edad, clase social, etnia, religión y orientación sexual. La Ley Maria da Penha fue creada para modificar la situación de violencia en que vivían las mujeres brasileñas. Entre 1998 y 2008, incorpora un nuevo paradigma al reconocer la violencia contra las mujeres como una violación de los derechos humanos y no como un crimen privado de menor gravedad. Se aplica así a la violencia contra las mujeres el régimen jurídico aplicable a las violaciones de los derechos humanos (MARÍA CRISTINA BENAVENTE, ALEJANDRA VALDÉS, 2014). El objetivo de la Ley es crear mecanismos para prevenir la violencia en el espacio privado contra las mujeres, según lo establecido en el párrafo 8 del artículo 226 de la Constitución, en la Convención sobre la Eliminación de Todas las Formas de Discriminación Contra la Mujer y en la Convención de Belém do Pará.

Otro de sus objetivos es garantizar la protección y asistencia a las mujeres a través de medidas integradas -en los ámbitos policial, judicial, de asistencia social y de salud- de prevención, protección, orientación y urgencia, prendiendo ser un instrumento de cambio político, jurídico y cultural (MARÍA CRISTINA BENAVENTE, ALEJANDRA VALDÉS, 2014). El Plan Nacional 2011-2015 y el Programa "Mujeres: Vivir sin Violencia" guardan coherencia con la Ley Maria da Penha la cual establece, en su artículo 8o, que: la política pública dirigida a frenar la violencia doméstica y contra las mujeres se implementará a través de un conjunto articulado de acciones entre el Gobierno Federal, los Estados Federativos, los
Municipios y acciones no gubernamentales y de manera coordinada con el Poder Judicial, el Ministerio Público y acciones de seguridad pública, asistencia social, salud, educación, trabajo y vivienda. Dicho conjunto de políticas públicas guarda consistencia con los instrumentos legales a nivel regional e internacional que el país ha adherido y ratificado.

Ambas políticas adoptan el enfoque de derechos humanos y tienen como población objetivo a las mujeres adultas ya que la violencia contra las niñas y adolescentes forma parte de la agenda de la Secretaría Nacional de Derechos Humanos. No obstante, algunas de las acciones de ambas políticas públicas también benefician a las niñas y adolescentes, en especial, aquellas relacionadas con la organización y la humanización de la atención a las víctimas/ sobrevivientes de violencia sexual (PNUD, ONU, 2014). El trabajo del movimiento de derechos de las mujeres, la Secretaría Especial de Políticas para as Mulheres (Secretaría Especial de Políticas para las Mujeres), y el movimiento feminista de Brasil, llevó a que se propusiera al Congreso Nacional una Ley sobre violencia familiar contra la mujer, Ley que el movimiento de mujeres pedía desde la década de 1980 . Influyó también la larga lucha de María da Penha, una mujer brasileña víctima de violencia y de intento de asesinato por parte de su esposo, que, con el apoyo del Centro por la Justicia y el Derecho Internacional (CEJIL) y el Comité para América Latina y el Caribe para la Defensa de los Derechos de la Mujer (CLADEM), denunció a Brasil ante la Comisión Interamericana de Derechos Humanos (CIDH) por no tomar medidas efectivas para prevenir y sancionar la violencia, y por el patrón de impunidad establecido en la respuesta del Poder Judicial frente a las agresiones de este tipo. La Comisión responsabilizó a Brasil por violación de los derechos humanos, aplicando, por primera vez desde su entrada en vigor, la Convención Interamericana para Prevenir, Sancionar y Erradicar la Violencia contra la Mujer (Convención de Belém do Pará), y exhortó al Estado brasileño a adoptar medidas para garantizar el efectivo castigo, 
prevención y erradicación de la violencia contra las mujeres (Observatorio de Igualdad de Género, 2014).

\section{México}

Se debe resaltar que Convención sobre la Eliminación de Todas las Formas de Discriminación contra la Mujer, ONU (CEDAW) y la Convención Interamericana para Prevenir, Sancionar y Erradicar la Violencia contra la Mujer (Belém do Pará) fueron hitos en la historia. Los cuales detonaron la posibilidad de crear numerosos procesos de configuración de políticas públicas en el orden nacional alrededor de la igualdad y la garantía de los derechos de las mujeres. En México es posible destacar en los últimos años la existencia del Programa Nacional para la Igualdad de Oportunidades y no Discriminación contra las Mujeres 2013-2018. De acuerdo con la legislatura del Senado mexicano, el Programa para la Igualdad entre Mujeres y Hombres tiene como objetivo general: Institucionalizar la perspectiva de género en el Senado de la República, ya que este se encuentra alineado al Plan Nacional de Desarrollo 2013 - 2018 y al Programa Nacional para la Igualdad de Oportunidades y No Discriminación contra las Mujeres 2013 - 2018 (Senado de la Republica de México, 2015), con el fin de avanzar unísonamente hacia la igualdad entre mujeres y hombres en México a partir de 10 estrategias:

Estrategia 1: Transversalizar la perspectiva de género en las políticas institucionales, la programación y presupuesto del Senado de la República.

Estrategia 2: Integrar el lenguaje incluyente en el uso cotidiano de la gestión, documentos y comunicación institucional del Senado de la República.

Estrategia 3: Promover un clima laboral libre de violencia y discriminación donde prevalezcan las condiciones laborales igualitarias y se promueva el reconocimiento y calidad laboral.
Estrategia 4: Instituir políticas y acciones afirmativas que coadyuven al reparto equitativo de las responsabilidades familiares entre el Estado, mercado y miembros de las familias, con el fin de coadyuvar a que el personal que labora en el Senado de la República logre un mejor desarrollo profesional, eleve su calidad de vida y se mejoren las condiciones de competencia y productividad laboral.

Estrategia 5: Impulsar que la selección de personal, los ascensos, salarios y prestaciones se otorguen con base a criterios de transparencia e igualdad de género.

Estrategia 6: Crear un programa anual de capacitación y profesionalización en igualdad de género y derechos humanos de las mujeres, que le permita al personal técnico y operativo adquirir nuevas herramientas, potenciar sus habilidades y experiencia profesional para beneficio del quehacer institucional.

Estrategia 7: Diseñar y establecer un mecanismo preciso y transparente para la prevención, atención y eliminación de prácticas violentas, el acoso y hostigamiento sexual.

Estrategia 8: Realizar investigaciones desde la perspectiva de género, sobre la situación de las mujeres en México, con el fin de apoyar en la generación de conocimiento que permita apoyar en la toma de decisiones para el cierre de brechas de desigualdad de género.

Estrategia 9: Desarrollar acciones con las organizaciones de la sociedad civil, instituciones académicas y organismos internacionales que trabajen temas de igualdad de género, con el fin de vincularlas con el trabajo que realiza la Unidad de Género.

Estrategia 10: Generar un sistema de evaluación con perspectiva de género del trabajo legislativo y la cultura institucional del Senado de la República. 
(Senado de la Republica de México, 2015)

En esa medida, el movimiento feminista ha sido determinante para el reconocimiento de los derechos de las mujeres. A la vez, ha sido un actor clave en la conformación de políticas de igualdad de género que logra establecer alianzas con actores políticos, sociales y académicos, así como con organismos nacionales e internacionales e incidir en el debate público y legislativo, para luego hacer seguimiento de la aplicación de las políticas (MARÍA CRISTINA BENAVENTE, ALEJANDRA VALDÉS, 2014).

\section{CONCLUSIONES}

En los últimos diez años, ha ido en aumento los distintos puntos de vista y posiciones críticas con respecto a los movimientos feministas latinoamericanos. Mediante los cuales, se ha logrado fortalecer los estudios académicos que vinculan aspectos conceptuales, prácticos y teóricos propios de las experiencias de las mujeres. Por ello, algunas de las luchas feministas confluyen y se apoyan en las demandas de otros sectores sociales, sobre todo en contextos donde se vulneraron DD. HH $y$, de manera exacerbada, los derechos de mujeres, niñas y adolescentes, tanto en ámbitos rurales como urbanos. Las mujeres, involucrando esfuerzos para brindar alternativas institucionales de existencia política, algunas vinculadas al sector público, lograron una influencia cualificada en el diseño e implementación de políticas públicas, específicamente a Mujeres y Equidad de Género. Los movimientos sociales de mujeres y mujeres feministas, de esa forma, posibilitan otra forma de estudiar, interpretar y definir la historia política local, en tanto que se politizan acciones colectivas que antes pasaban desapercibidas o no merecían tal estatus. Sobre experiencias de mujeres organizadas en torno al movimiento social de mujeres, sería "pertinente aceptar que ha significado más una redefinición del poder político y la forma de entender la política, que una búsqueda del poder o de la representación en la política formal" (Acosta, 2012).
Hablar de políticas públicas no siempre es fácil. Implica la interacción, confrontación y armonización de una serie de poderes, factores, componentes económicos, políticos, el poder, saber, cultura, clase, medioambiente, género. Es un campo de múltiples luchas, el ejercicio de la dominación, de producción de la sujeción, de resistencia, de relativización y profundización de los conflictos sociales, de defensa de los derechos, de configuración de la emergencia social, de visibilización y resolución de requerimientos sociales y culturales, de construcción de entidades y de transformación de las funciones de Estado (Rodríguez C. M., 2018). Los ciudadanos pueden realizar seguimiento de las políticas públicas tratando de elaborar un diagnóstico de carácter explicativo sobre la gestión de dicha política, y verificando si se cumplen los objetivos estatales; lo que propone la política, o que persigue realmente; describe el cómo ha intervenido el estado en la sociedad. En tal sentido, es posible afirmar como el proceso de ejecución de la política pública es el reflejo, y la síntesis, de los intereses del sistema político que se expresó en su formulación; los intereses del sistema administrativo-que también entran a jugar en la implementación- haciendo que ésta, por momento, se desvíe en uno u otro sentido; y también, por supuesto, los intereses de las fuerzas sociales donde están, al fin de cuentas, las personas que reciben las acciones concretas y pueden reaccionar a favor o en contra de ellas (Salazar Vargas, 2009). El fortalecimiento de la estrategia de litigio en los casos de violencia sexual, en la Secretaría Distrital de la Mujer de Bogotá, debe ser un elemento central y prioritario para reducir las altas tasas de violencia sexual en Bogotá. Lo cual permite con ello, la reducción de los niveles de impunidad, el fortalecimiento de la autonomía y poder de decisión de las mujeres, el acceso a la justicia, y la capacidad de denuncia y sanción de este tipo de delitos.

\section{RECOMENDACIONES}

La estrategia de litigio sigue siendo insuficiente para la cobertura. Debe observarse a mediano corto plazo la posibilidad de ampliar el presupuesto y el 
número de abogadas y abogados en esta estrategia de litigio y de realizar trabajo interinstitucional de fortalecimiento externo a través de consultorios jurídicos de universidades. Los cuales se encargarían del acompañamiento jurídico con asesoría y atención directa de las abogadas titulares de los casos de violencia sexual. Avanzar en alianzas con organizaciones no gubernamentales que realicen litigio en casos de violencia sexual y ejerzan representación judicial de estas mujeres con amplia experiencia en este tema. Finalmente, en relación y convenio interinstitucional con entidades como la Defensoría del Pueblo, realizar acompañamiento de víctimas en casos penales con el propósito de ampliar la cobertura en términos de atención y representación judiciales de estas mujeres víctimas de violencia sexual.

Como se encuentra planteada la Política Mujer y Equidad de Género, desde su conformación histórica, hilos de ideales y luchas políticas de los movimientos sociales de mujeres en Bogotá, es necesario que la Secretaría Distrital de la Mujer trabaje desde todas sus esferas y escalas, bajo una perspectiva política feminista $\mathrm{y}$ de género que comprenda de manera multi- contextual, la situación de los derechos humanos de las mujeres. En tal sentido, omitir la necesidad de una perspectiva y una posición política, puede poner en riesgo el reconocer $y$ garantizar los derechos de las mujeres y que se transformen las condiciones históricosociales de subordinación y exclusión. La teoría feminista, resultado de la movilización de mujeres a través de los años, intentó definir con el tiempo los derechos humanos desde una perspectiva universal e igualitaria, igualdad que a la vez considere la diferencia y una valoración de la humanidad de las mujeres.

En Colombia la influencia del movimiento de mujeres y del movimiento feminista, alimentaron espacios gubernamentales, desde el fortalecimiento a instituciones del Estado en generar enfoques rigurosos hacia las afectaciones de los derechos humanos de las mujeres. Ello con el propósito de transformar políticas, consolidar y permitir que se desarrollaran unas nuevas, también para vigilar su cumplimiento. La Secretaría Distrital de la Mujer y la misma política pública de Mujeres y Equidad de Género, son fruto de dichos esfuerzos.

\section{Tabla 1. Secretarías de la Mujer ubicadas en el territorio colombiano, año 2019}

\begin{tabular}{|l|l|l|l|}
\hline \multicolumn{2}{|c|}{ SECRETARÍAS DE LA MUJER UBICADAS EN EL TERRITORIO COLOMBIANO, AÑO 2019 } \\
\hline \multicolumn{1}{|c|}{ ENTIDAD } & DEPARTAMENTO & \multicolumn{1}{|c|}{ MISIÓN U OBJETIVO } & $\begin{array}{c}\text { SECRETARIA A } \\
\text { CARGO O PROFESIONAL } \\
\text { ENCARGADO }\end{array}$ \\
\hline $\begin{array}{l}\text { Secretaría de las } \\
\text { Mujeres }\end{array}$ & Antioquia & $\begin{array}{l}\text { La misión de la Secretaría es la de contribuir } \\
\text { a la igualdad de derechos y oportunidades } \\
\text { entre mujeres yombres ya la disminución de } \\
\text { prácticas discriminatorias que atenten contra } \\
\text { el desarrollo político, social, económico y } \\
\text { cultural de las mujeres del Municipio de de } \\
\text { Medellín, a través de la implementación de } \\
\text { la Política Pública para las mujeres urbanas } \\
\text { y rurales de la ciudad - Acuerdo 22 de 2003 } \\
\text { (Alcaldía de Medellín, 2019). }\end{array}$ \\
\hline
\end{tabular}




\begin{tabular}{|c|c|c|c|}
\hline \multicolumn{4}{|c|}{ SECRETARÍAS DE LA MUJER UBICADAS EN EL TERRITORIO COLOMBIANO, AÑO 2019} \\
\hline ENTIDAD & DEPARTAMENTO & MISIÓN U OBJETIVO & $\begin{array}{c}\text { SECRETARIA A } \\
\text { CARGO O PROFESIONAL } \\
\text { ENCARGADO }\end{array}$ \\
\hline $\begin{array}{l}\text { Secretaría de la } \\
\text { Mujeres y Equidad de } \\
\text { Género }\end{array}$ & Atlántico & $\begin{array}{l}\text { Su objetivo es dar cumplimiento a la } \\
\text { reivindicación de las mujeres como sujetos } \\
\text { plenos de derechos humanos. Es así } \\
\text { como, el } 5 \text { de diciembre de 2012, se crea } \\
\text { la Secretaría de la Mujeres y Equidad de } \\
\text { Género impulsando la participación y el } \\
\text { empoderamiento de las mujeres en ámbitos } \\
\text { políticos, culturales, sociales y económicos } \\
\text { (Gobernación Atlántico, 2013). }\end{array}$ & $\begin{array}{l}\text { Zandra Margarita Vásquez } \\
\text { Hernández }\end{array}$ \\
\hline $\begin{array}{l}\text { Secretaría de } \\
\text { Desarrollo Social y } \\
\text { Equidad de Género } \\
\text { de Arauca }\end{array}$ & Arauca & & $\begin{array}{l}\text { Eyegma Yovelys Chavez } \\
\text { Translavilla }\end{array}$ \\
\hline $\begin{array}{l}\text { Secretaría de } \\
\text { Desarrollo Social y } \\
\text { familia de Caldas }\end{array}$ & Caldas & $\begin{array}{l}\text { La Secretaría de Integración y Desarrollo } \\
\text { Social de la Gobernación de Caldas, tiene } \\
\text { como misión institucional formular, dirigir, } \\
\text { coordinar e implementar una política social } \\
\text { tendiente a disminuir las distintas expresio- } \\
\text { nes de pobreza y las inequidades sociales, } \\
\text { económicas, culturales, productivas y demo- } \\
\text { gráficas. Facilitando canales de organización, } \\
\text { desarrollo, proyección y fortalecimiento de } \\
\text { las comunidades (Gobierno de Caldas, 2019). }\end{array}$ & $\begin{array}{l}\text { Gloria Liliana López } \\
\text { Castrillón }\end{array}$ \\
\hline $\begin{array}{l}\text { Secretaría de la Mujer } \\
\text { de Cauca }\end{array}$ & Cauca & $\begin{array}{l}\text { Brindar asistencia técnica a los entes munici- } \\
\text { pales para promover, articular y territorializar } \\
\text { la política pública de las mujeres caucanas } \\
\text { "Por la Dignidad de las Mujeres en el Cauca" } \\
\text { y velar por: reducir las brechas inequitativas } \\
\text { de género, el goce efectivo de derechos y tra- } \\
\text { bajar a favor de las mujeres más vulneradas } \\
\text { (Secretaría de la Mujer del Cauca, 2019). }\end{array}$ & Elvia Rocío Cuenca Bonilla \\
\hline $\begin{array}{l}\text { Secretaría de la } \\
\text { Mujeres y Equidad de } \\
\text { Género }\end{array}$ & Cundinamarca & $\begin{array}{l}\text { La Misión de Secretaría es implementar, } \\
\text { monitorear y evaluar la política pública de } \\
\text { Mujer, Equidad de Género e Igualdad de } \\
\text { Oportunidades, realizar actividades que } \\
\text { brinden condiciones de equidad e igual- } \\
\text { dad de oportunidades para las mujeres de } \\
\text { Cundinamarca, propiciando la adecuación } \\
\text { de las instituciones y la transformación de } \\
\text { las prácticas culturales que menoscaban sus } \\
\text { derechos, con el propósito de lograr el me- } \\
\text { joramiento integral y el pleno ejercicio de los } \\
\text { derechos de las mujeres (Secretaría de la mu- } \\
\text { jer de Cundinamarca, 2019). }\end{array}$ & $\begin{array}{l}\text { Ana Esperanza Ragones } \\
\text { muñoz }\end{array}$ \\
\hline
\end{tabular}




\begin{tabular}{|c|c|c|c|}
\hline \multicolumn{4}{|c|}{ SECRETARÍAS DE LA MUJER UBICADAS EN EL TERRITORIO COLOMBIANO, AÑO 2019} \\
\hline ENTIDAD & DEPARTAMENTO & MISIÓN U OBJETIVO & $\begin{array}{c}\text { SECRETARIA A } \\
\text { CARGO O PROFESIONAL } \\
\text { ENCARGADO }\end{array}$ \\
\hline $\begin{array}{l}\text { Secretaría de la } \\
\text { Mujeres y Equidad de } \\
\text { Género del Meta }\end{array}$ & Meta & $\begin{array}{l}\text { Tiene como objetivo ser la rectora de la polí- } \\
\text { tica pública para la equidad de género, en el } \\
\text { departamento, sea la encargada de contribuir } \\
\text { a la igualdad de derechos y oportunidades } \\
\text { entre mujeres y hombres y a la disminución } \\
\text { de prácticas discriminatorias que afectan el } \\
\text { desarrollo político, social, económico y cul- } \\
\text { tural de las mujeres del departamento. Todo } \\
\text { ello, a través del diseño, implementación, } \\
\text { coordinación, articulación, monitoreo y ase- } \\
\text { soría de las políticas, planes, programas, pro- } \\
\text { yectos y acciones que llevan a la promoción, } \\
\text { prevención, garantía y protección de sus de- } \\
\text { rechos (Secretaría de la Mujeres y Equidad de } \\
\text { Género, 2019). }\end{array}$ & Norma Lucia Vélez Ortega \\
\hline $\begin{array}{l}\text { Secretaría de Equidad } \\
\text { de Género e inclusión } \\
\text { social de Nariño }\end{array}$ & Nariño & & Elena Pantoja Guerrero \\
\hline $\begin{array}{l}\text { Secretaría de la } \\
\text { Mujer de Norte de } \\
\text { Santander }\end{array}$ & Norte de Santander & $\begin{array}{l}\text { Contribuir a la igualdad de derechos y opor- } \\
\text { tunidades, a la disminución de prácticas } \\
\text { discriminatorias que atenten contra el desa- } \\
\text { rrollo económico, social, político y cultural } \\
\text { de las mujeres del Departamento Norte de } \\
\text { Santander, a través del diseño, implementa- } \\
\text { ción, coordinación, asesoría y ejecución de } \\
\text { las políticas, planes, proyectos y programas } \\
\text { del gobierno departamental que favorez- } \\
\text { ca el reconocimiento del sujeto mujer y las } \\
\text { transformaciones de las relaciones de género } \\
\text { (Gobernación de Norte de Santander,2019). }\end{array}$ & $\begin{array}{l}\text { Herling Ximena Fernández } \\
\text { Maldonado }\end{array}$ \\
\hline $\begin{array}{l}\text { Secretaría de la } \\
\text { Mujer, Equidad de } \\
\text { Género y Diversidad } \\
\text { Sexual del Valle del } \\
\text { Cauca }\end{array}$ & Valle del Cauca & $\begin{array}{l}\text { La misión de la Secretaría de Mujer, Equidad } \\
\text { de Género y Diversidad Sexual es adelantar } \\
\text { procesos de desarrollo integral que conso- } \\
\text { liden la perspectiva de género y diversidad } \\
\text { sexual, mediante el cumplimiento de los } \\
\text { principios democráticos de igualdad, justicia, } \\
\text { equidad, tolerancia, respeto a la diferencia, } \\
\text { integridad, seguridad, participación políti- } \\
\text { ca y transversalidad (Artículo 127: Decreto } \\
\text { Departamental 1138 de 2016). }\end{array}$ & $\begin{array}{l}\text { Luz Adriana Londoño } \\
\text { Ramírez }\end{array}$ \\
\hline $\begin{array}{l}\text { Secretaría Distrital de } \\
\text { la Mujer }\end{array}$ & Cundinamarca & $\begin{array}{l}\text { LLiderar, orientar y coordinar la formulación, } \\
\text { implementación, seguimiento y evaluación } \\
\text { de la Política Pública de Mujeres y Equidad de } \\
\text { Género. Así como la transversalización de los } \\
\text { enfoques de derechos de las mujeres, de gé- } \\
\text { nero y diferencial, en los planes, programas, } \\
\text { proyectos y políticas públicas distritales, para } \\
\text { la protección, garantía y materialización de } \\
\text { los derechos humanos de las mujeres en las } \\
\text { diferencias y diversidades que las constitu- } \\
\text { yen, promoviendo su autonomía y el ejercicio } \\
\text { pleno de su ciudadanía en el Distrito Capital } \\
\text { (Secretaria Distrital de la Mujer, 2019). }\end{array}$ & Ángela Anzola de Toro \\
\hline
\end{tabular}

\section{Elaboración propia}




\section{BIBLIOGRAFÍA}

» ACOSTA, G. S. (2012). ACCIONES COLECTIVAS DEL MOVIMIENTO DE MUJERES Y DEL MOVIMIENTO FEMINISTA EN CALI: APUNTES DESDE LA HISTORIOGRAFÍA FEMINISTA. FLACSO.

» AGUILAR, Y. A. (2010). LA ATENCIÓN INTEGRAL A MUJERES VÍCTIMAS DE VIOLENCIA SEXUAL, UN COMPROMISO INTERINSTITUCIONAL EN LA CIUDAD DE BOGOTÁ. Trabajo de grado para optar el título de: MAGISTRA EN POLÍTICA SOCIAL. BOGOTÁ, COLOMBIA.

» Amaya, C. (2019). Comunicación personal.

» Amaya, C. (2019). Comunicación personal. (F. Garzón, Entrevistador)

»Andrieu Sanz, R. y. (2005). Normalización del "género" y problemas de legitimidad de las teorías y luchas feministas: elementos para un debate. En Antropología feminista y/o del género: legitimidad, poder y usos políticos (págs. 9-41).

» Arendt, H. (1994). Derecho a tener derechos.

» Barón y Muñoz, M. G. (2016). Aciertos y fallas en la implementación de la Política de Mujeres y Equidad de Género de Bogotá.

» Barragán y Alfonso Ávila, F. y. (2010). Lineamientos de política pública para la prevención, protección, atención y sanción de las violencias basadas en género y contra las mujeres en Colombia. Bogotá.

» Barrantes, G. C. (08 de 03 de 2016). La museología centroamericana como reproductora del discurso eurocentrista, un análisis de los catálogos de la participación de Centroamérica en las exposiciones universales de París, Madrid, Chicago, y Guatemala a finales del siglo XIX. costa rica.

» Bogotá, C. d. (07 de 04 de 2015). Acuerdo 583 de 2015 Concejo de Bogotá D.C. Obtenido de Régimen Legal de Bogotá: https://www.alcaldiabogota.gov.co/sisjur/ normas/Norma1.jsp?i=61237

» BOGOTÁ, C. D. (2015). COLECCIÓN DE LEGISLACIÓN COLOMBIANA. Obtenido de ACUERDO 631 DE 29 DE DICIEMBRE DE 2015.

»Canterla, C. (2002). Mujer y derechos humanos: universalismo y violencia simbólica de género. Discursos, realidades, utopías: la construcción del sujeto femenino en los siglos. Bogotá.

» CASTRO, M. F. (2017). Feminicidios en Caldas un fenómeno de la Violencia de Género. Tesis Como requisito parcial para optar al título de Abogada. Manizales, Colombia.

» Chávez Carapia, J. (2016). Políticas públicas y violencia de género en México. México.

» Colombia, U. C. (2017). La investigación cualitativa: Una investigación en marcha sobre el hecho social. Ciencias sociales, derecho y ciencias políticas.

» Comins-Mingol, I. (enero de 2008). ResearchGate. Obtenido de https://www. researchgate.net/publication/274458539_Los_Derechos_Humanos_y_la_Eliminacion_de_la_Violencia_contra_la_Mujer

» Comisión Nacional De Género De La Rama Judicial. (2016). Lineamientos de Atención y protección a las mujeres víctimas. Bogotá: Comisión Nacional De Género De La Rama Judicial - CNGRJ. 
» Congreso de la República. (2008). Ministerio TIC. Obtenido de LEY 1257 DE 2008: https://www.mintic.gov.co/portal/604/articles-3657_documento.pdf

» Corporación Casa de la Mujer y Grupo SaludCoop. (2007). Entre mujeres: Conversatorios para la prevención de la violencia intrafamiliar y la violencia sexual contra. Bogotá.

» Cubides, P. A. (2015). El sector público estatal y las competencias. Derecho y Realidad, 8.

» Cubillos, M. C. (2017). El papel de la participación ciudadana en las políticas públicas, bajo el actual escenario de la gobernanza.

» Departamento Administrativo de Bienestar Social del Distrito y Corporación Casa de la Mujer. (2007). Talleres de formación para la detección, promoción de denuncia y sanción de la violencia intrafamiliar de los delitos sexuales. Bogotá.

» Domingo Carbonero Muñoz, Neus Caparrós. (2015). Métodos y técnicas de investigación en Trabajo social. Madrid.

» EDUCACIÓN, M. D. (2019). DOCUMENTO DE ORIENTACIONES DE POLÍTICA PARA LA PROMOCIÓN DE DERECHOS Y LA PREVENCIÓN DETENCIÓN DE VIOLENCIAS EN LA ESCUELA.

» Forenses, I. M. (2017). Forensis, 2017. 2017: Instituto Medicina Legal y Ciencias Forenses.

» Fries, L. (1999). Los derechos humanos de las mujeres. En c. Gioconda Herrera, Las fisuras del patriarcado, Reflexiones sobre Feminismo y Derecho.

» Fries, L. (2013). Los derechos humanos de las mujeres.

» Garzón, F. (07 de 2020). El rol de la secretaría de la mujer ante delitos de violencia sexual. Bogotá.

» Gómez, M. V. (26 de 12 de 2018). Transmilenio: un recorrido por el acoso a mujeres. El tiempo, pág. 1.

» Grau, M. (2013). La memoria histórica, ¿activo transformador de la desigualdad de género? En M. Grau, Análisis crítico del discurso del Centro de memoria histórica en Colombia a partir de una mirada de género (págs. 11,). Barcelona: consejo editorial.

» Hernández, M. E. (2018). Acciones de movilización de las mujeres dentro de un proceso de construcción e implementación de la política pública. En T. P. Franklin Gil Hernández, Feminismos y estudios de género en Colombia: Un campo académico y político en movimiento. (pág. 94). Bogotá.

» Humanas, C. (2019). Encuesta de Prevalencia. Violaciones y Otras Violencias SAQUEN MI CUERPO DE LA GUERRA. Bogotá.

»Humanos, C. I. (2007). Informe Anual de la comisión interamericana de Derechos Humanos.

» Instituto Nacional de Medicina Legal. (2016). Forensis 2016. Bogotá: Instituto Nacional de Medicina Legal y Ciencias Forenses, grupo centro de referencia nacional sobre violencias.

» Instituto Nacional de Medicina Legal y Ciencias Forenses. (2018). Forensis 2018. Bogotá: Instituto Nacional de Medicina Legal y Ciencias Forenses. 
interior, M. d. (2017). Informe de gestión 2. Bogotá.

» Jelin, E. (2001). Exclusión, memorias y luchas políticas. Buenos Aires: Clacso.

» Las medidas de protección a mujeres víctimas. (2008). Artículo 2 y 3 de la Ley 1257.

» Mala Htun, C. O. (2014). Movilización feminista y políticas sobre violencia contra las mujeres.

» MARÍA CRISTINA BENAVENTE, ALEJANDRA VALDÉS. (2014). Políticas públicas Para la Igualdad de Género.

» María Mercedes Lafaurie, Erika Giovanna Veloza. (2010). Trazando una ruta para motivar reflexiones en torno a las violencias basadas en género. Bogotá.

» Martínez, M. M. (2010). Trazando una ruta para motivar reflexiones en torno a las violencias basadas en género. Bogotá: Ministerio de protección social.

» Medina, 0. (20 de 08 de 2019). Comunicación personal .

$»$ Memoria, C. N. (2017). La guerra inscrita en el cuerpo. Informe nacional de violencia sexual en el conflicto Armado. Bogotá.

» Ministerio de Educación. (2019). ORIENTACIONES DE POLÍTICA PARA LA PROMOCIÓN DE DERECHOS Y LA PREVENCION DETECCION DE VIOLENCIAS EN LA ESCUELA.

» MONTOYA, R. O. (2017). Feminicidio, Poder, desigualdad, subordinación e impunidad: no más Invisibilidad. En R. O. MONTOYA. Universidad Católica Luis Amigo.

» Montoya, R. O. (2017). Feminicidio: poder, desigualdad, subordinación e impunidad, no más invisibilidad. Bogotá: Universidad Católica Luis Amigo.

» Morgan Planas, I. (2009). Violencia sexual y nuevas guerras.

» Mujer, C. S. (2011). OBSTÁCULOS PARA EL ACCESO A LA JUSTICIA DE LAS MUJERES VICTIMAS DE VIOLENCIA SEXUAL EN COLOMBIA. Bogotá: sisma mujer.

» Mujer, S. y. (2007). Reto del sector salud, para la atención y prevención de la violencia intrafamiliar y la violencia sexual contra niñas y niños. Bogotá.

» Mujer., D. A. (2007). Talleres de formación para la detención, promoción de denuncia y sanción de la violencia intrafamiliar de los delitos sexuales. Bogotá.

» Observatorio de Igualdad de Género. (2014). La Ley 11.340 Maria da Penha (2006), Un avance en la garantía de la autonomía.

» Oficina del Alto comisionado de las Naciones Unidas para los Derechos Humanos. (2019). Serie de información sobre salud y derechos sexuales y reproductivos. Europa: Oficina del Alto comisionado de las Naciones Unidas para los Derechos Humanos.

» Pineda y Otero, D. J. (2004). Género, violencia intrafamiliar e intervención pública en Colombia. Revista de estudios sociales, 19-31.

» PNUD, ONU. (2014). Del compromiso a la acción.

» Profamilia. (2019). Prevención y Abordaje de la violencia sexual en personas con discapacidad desde un enfoque de determinantes sociales. Bogotá: Asociación Profamilia. 
» PUEBLO, D. D. (2011). "Las mejores prácticas en la aplicación de los valores tradicionales".

» RÍOS, M. L. (1996). El derecho humano de las mujeres. Cátedra Unesco, 4.

» Rodríguez, C. M. (2018). Análisis de la implementación de la política pública de la política pública de seguridad ciudadana. Tesis Doctoral. Madrid, España.

» Rodríguez, G. P. (2016). EL CORTO RECORRIDO DEL FEMINICIDIO EN COLOMBIA. Universidad de los Andes.

» Rodríguez, J. F. (2017). Economía social y solidaria. Bogotá: Pontificia Universidad Javeriana.

» Salazar Vargas, C. (2009). La evaluación y el análisis de políticas públicas.

» Salgado, M. J. (2000). Garantías constitucionales y derechos humanos de las mujeres. Quito, Ecuador: Garantías constitucionales y derechos humanos de las mujeres.

» Sánchez, O. A. (2008). Las Violencias contra las mujeres en una sociedad de Guerra. Ruta Pacífica de las Mujeres.

» Santander, Jaime Torres Melo y Jairo. (2013). Introducción a las políticas públicas, Conceptos y herramientas desde la relación entre el estado y ciudadanía. Bogotá: IEMP Ediciones.

» Secretaria de la Mujer. (2012). Acuerdo 490. Acuerdo 490 de 2012 creación de la secretaria de la mujer.

» Secretaría Distrital de la Mujer. (2017). Boletín informativo.

» Secretaría Distrital de la Mujer. (2019). Índice sintético de machismo 2019, documentos de lectura, descripción y análisis, marco conceptual y justificación de cambios.

» Secretaría Distrital de la Mujer. (2019). Informe de Gestión 2016-2019. Bogotá.

» Segato, R. (2017). La Guerra contra las Mujeres. Epublibre.

» Senado de la Republica de México. (2015). Programa para la igualdad del género del senado en México.

» Sequeira y Stella, C. (2012). Família e violência: resquícios da cultura patriarcal. Emancipação. São Paulo.

» Tsuji, T. y. (2014). Aportes para comprender a la violencia intrafamiliar.

» UNFPA, Ministerio de la protección social. (2011). Modelo de Atención para Víctimas de violencia sexual.

» Valencia Agudelo, G. D. (2011). Contribuciones de las políticas públicas al estudio del Estado. Semestre económico. Bogotá.

» Vargas Velásquez, A. (1999). Notas sobre el estado y las políticas públicas. Bogotá.

»Vasco, C. E. (2003). El debate recurrente sobre la investigación cuantitativa y la cualitativa. Revista Nómadas número 18, Universidad Central.

» Vásquez, L. Y. (2007). Las políticas públicas de mujer y género en Bogotá: tensiones y aciertos. Revista Colombiana de Sociología.

» Veeduría Distrital. (2017). Descripción y Análisis de la política Pública de Muje- 
res y equidad de Género del Distrito Capital. Bogotá: Veeduría Distrital.

»Velosa, J. (18 de 07 de 2019). Comunicación personal.

"Vicente Arregui, G. I. (2006). Introducción: las mujeres en la sociedad y en el derecho, Latinoamérica y Europa. Araucaria. Revista Iberoamericana de filosofía, política y humanidades, 100-107. 